\title{
Th1 memory differentiates recombinant from live herpes zoster vaccines
}

\author{
Myron J. Levin,, ${ }^{1,2}$ Miranda E. Kroehl, ${ }^{3}$ Michael J. Johnson, ${ }^{1}$ Andrew Hammes, ${ }^{3}$ Dominik Reinhold, ${ }^{3}$ Nancy Lang, ${ }^{1}$ \\ and Adriana Weinberg ${ }^{1,2,4}$ \\ 1Department of Pediatrics, and 2Department of Medicine, University of Colorado School of Medicine, ${ }^{3}$ Department of Biostatistics and Informatics, University of Colorado School of Public Health, and \\ ${ }^{4}$ Department of Pathology, University of Colorado School of Medicine, University of Colorado Denver, Anschutz Medical Campus, Denver, Colorado USA.
}

\begin{abstract}
The adjuvanted varicella-zoster virus (VZV) glycoprotein E (gE) subunit herpes zoster vaccine (HZ/su) confers higher protection against $\mathrm{HZ}$ than the live attenuated zoster vaccine (ZV). To understand the immunologic basis for the different efficacies of the vaccines, we compared immune responses to the vaccines in adults 50 to 85 years old. gE-specific T cells were very low/undetectable before vaccination when analyzed by FluoroSpot and flow cytometry. Both ZV and $\mathrm{HZ} / \mathrm{su}$ increased gE-specific responses, but at peak memory response (PMR) after vaccination (30 days after ZV or after the second dose of $\mathrm{HZ} / \mathrm{su}$ ), gE-specific $\mathrm{CD}^{+}$and $\mathrm{CD}^{+} \mathrm{T}$ cell responses were 10 -fold or more higher in $\mathrm{HZ} / \mathrm{su}$ compared with $\mathrm{ZV}$ recipients. Comparing the vaccines, T cell memory responses, including gE-IL-2+ and VZV-IL-2+ spot-forming cells (SFCs), were higher in $\mathrm{HZ}$ /su recipients and cytotoxic and effector responses were lower. At 1 year after vaccination, all gE-Th1 and VZV-IL-2+ SFCs remained higher in HZ/su compared with ZV recipients. Mediation analyses showed that IL-2+ PMR were necessary for the persistence of Th1 responses to either vaccine and VZV-IL-2+ PMR explained $73 \%$ of the total effect of $\mathrm{HZ} / \mathrm{su}$ on persistence. This emphasizes the biological importance of the memory responses, which were clearly superior in $\mathrm{HZ}$ /su compared with ZV participants.
\end{abstract}

\section{Introduction}

Herpes zoster (HZ) occurs when varicella-zoster virus (VZV) latent in sensory ganglia reactivates and replicates to cause dermatomal pain and a vesicular rash $(1,2)$. These events follow when an essential component or components of VZV-specific cell-mediated immunity (CMI) fall below a critical level, which typically happens when VZV-specific CMI is compromised by disease, medical treatment, or aging (3-7). The live attenuated zoster vaccine $(\mathrm{ZV})$ boosts VZV-specific CMI in elderly vaccinees, which explains the efficacy of the vaccine $(8,9)$. However, efficacy against $\mathrm{HZ}$ is limited to $51 \%$ in vaccinees older than 60 years of age (yoa) and is lower as the age at the time of vaccination increases $(9,10)$. Moreover, the protection provided by $\mathrm{ZV}$ declines significantly at 6 to 8 years after vaccination (11). The magnitude and duration of protection have been confirmed by effectiveness studies (12-14).

An alternative approach for prevention of $\mathrm{HZ}$ is the recently approved recombinant glycoprotein $\mathrm{E}$ ( $\mathrm{gE}$ ) subunit herpes zoster vaccine $(\mathrm{HZ} / \mathrm{su})$, which contains the $\mathrm{ASO}_{\mathrm{B}}$ adjuvant consisting of MPL (lipid A of bacterial lipopolysaccharide, a TLR4 agonist) and QS21 (a triterpene plant derivative in the family of saponins) pack-

\section{Related Commentary: p. 4245}

Conflict of interest: MJL and AW receive research support from GSK, Merck, and MedImmune. MJL is a consultant for Merck and GSK. MJL is listed as an inventor on the patent on Zostavax (no. 5,997,880).

Submitted: April 4, 2018; Accepted: July 13, 2018.

Reference information: / Clin Invest. 2018;128(10):4429-4440.

https://doi.org/10.1172/JCI121484. aged into liposomes (15). HZ/su provides $97 \%$ protection against $\mathrm{HZ}$ in vaccinees 50 yoa and older, including $89 \%$ efficacy in those 80 yoa and older, indicating that the efficacy of $\mathrm{HZ} / \mathrm{su}$ is minimally affected by the age of the vaccinee $(16,17)$. Moreover, this strong protective effect persisted for the 3.8 years of follow-up reported. $\mathrm{HZ} /$ su-induced immune responses remained robust for the duration of the pivotal trials and have been readily detected at 6 to 9 years after vaccination in long-term follow-up studies (18-20).

These very favorable clinical responses to $\mathrm{HZ} / \mathrm{su}$ are uniquely better compared with responses to other vaccines administered to older individuals $(21,22)$. It is likely that overcoming immune senescence derives from the inclusion in $\mathrm{HZ} / \mathrm{su}_{\text {of }} \mathrm{ASO}_{\mathrm{B}}(15,23-$ 25). The current report compares the immune responses elicited by $\mathrm{ZV}$ or $\mathrm{HZ} / \mathrm{su}$ in participants 50 to 59 and 70 to 85 yoa who had never received $\mathrm{HZ}$ vaccine and also compares immune responses to the 2 vaccines in an additional cohort of participants 70 to 85 yoa who had received $\mathrm{ZV} 5$ years or more prior to enrollment. The primary objective was to determine immunologic responses that best differentiated the 2 vaccines in individuals receiving $\mathrm{HZ}$ vaccine for the first time. Other objectives were to compare the responses elicited by $\mathrm{HZ} / \mathrm{su}$ in participants who had received $\mathrm{ZV}$ 5 or more years previously with responses of individuals receiving $\mathrm{HZ} / \mathrm{su}$ for the first time and to identify $\mathrm{CD} 8^{+} \mathrm{T}$ cell responses generated by $\mathrm{HZ} / \mathrm{su}$.

\section{Results}

Demographic characteristics. The study enrolled 160 participants (Table 1). The mean age was 70 years; 86 (52\%) were women, 152 (97\%) were white, and 156 (98\%) were non-Hispanic. The demo- 
Table 1. Demographic characteristics of study participants

$\begin{array}{llcc}\text { Characteristic } & & \text { HZ/su } & \text { ZV } \\ \text { Age, mean (SD) } & & 70.0(9.7) & 69.5(9.7) \\ \text { Sex, N (\%) } & \text { M } & 38(48) & 34(43) \\ & \text { F } & 41(52) & 45(57) \\ \text { Race, N (\%) } & \text { W } & 77(97.5) & 75(95) \\ & \text { NW } & 2(2.5) & 4(5) \\ \text { Ethnicity, N (\%) } & \text { H } & 1(1) & 2(2.5) \\ & \text { NH } & 78(99) & 77(97.5)\end{array}$

In each vaccine group, 79 of 80 completed all study visits. W, white; NW, nonwhite; $\mathrm{H}$, Hispanic; $\mathrm{NH}$, non-Hispanic.

graphic characteristics were similar between the 2 vaccine groups in each of the 3 subgroups: first time-immunized 50- to 59-yearold (young primary), first time-immunized 70- to 85-year-old (older primary), and 70- to 85-year- old individuals who received ZV 5 or more years before enrollment (older boosted).

$V Z V$ - and $g E$-specific Th1 responses to $\mathrm{HZ} /$ su and $Z V$ measured by FluoroSpot. VZV-IL-2 ${ }^{+}$and gE-IL-2 $2^{+}, \mathrm{VZV}-\mathrm{IFN}-\gamma^{+}$and gE-IFN- $\gamma^{+}$, and VZV-IL-2 ${ }^{+}$IFN- $\gamma^{+}$and gE-IL-2 ${ }^{+}$IFN- $\gamma^{+}$double-positive (DP) Th1 responses were measured before vaccination, 30 days after $\mathrm{ZV}$ or the first $\mathrm{HZ} / \mathrm{su}$ dose, 30 days after the second $\mathrm{HZ} / \mathrm{su}$ dose, and at 1 year after each vaccine (Supplemental Figure 1; supplemental material available online with this article; https://doi.org/10.1172/ JCI121484DS1). The primary immunogenicity outcome measures specified in the protocol were Th1 responses at the peak memory response (PMR) time point, which occurred at 30 days after $\mathrm{ZV}$ (26) and at 30 days after the second dose of HZ/su (Figure 1 and Supplemental Figure 2). At baseline, participants had robust VZVTh1 CMI (e.g., VZV-IL-2 mean \pm SEM $=168 \pm 17$ spot-forming cells [SFCs] $/ 10^{6}$ peripheral blood mononuclear cells [PBMCs]), but very low or undetectable gE-Th1 CMI (gE-IL-2 = $25 \pm 4$ SFCs $/ 10^{6}$ PBMCs). At PMR, ZV recipients reached $323 \pm 24 \mathrm{VZV}-\mathrm{IL}-2$ SFCs $/ 10^{6}$ PBMCs and $35 \pm 6$ gE-IL-2 SFCs $/ 10^{6}$ PBMCs, while HZ/ su recipients reached $426 \pm 30 \mathrm{VZV}-\mathrm{IL}-2$ and $475 \pm 36 \mathrm{gE}-\mathrm{IL}-2$ SFCs $/ 10^{6}$ PBMCs. It is important to note that responses were much lower after a single dose of $\mathrm{HZ} / \mathrm{su}$ than the PMR that occurred after the second dose $\left(226 \pm 23 \mathrm{VZV}-\mathrm{IL}-2\right.$ and $128 \pm 12 \mathrm{gE}-\mathrm{IL}-2 \mathrm{SFCs} / 10^{6}$ PBMCs). In fact, VZV-IL-2 responses after the first dose of $\mathrm{HZ} / \mathrm{su}$ were lower than those of $\mathrm{ZV}$ recipients, underscoring the importance of the second dose for the immunogenicity of HZ/su.
Figure 1. Kinetics of Th1 responses to $\mathrm{HZ} / \mathrm{su}$ and $\mathrm{ZV}$ measured by FluoroSpot. Data were derived from 158 participants equally distributed between those receiving ZV, administered at day 0 , and those receiving $\mathrm{HZ} / \mathrm{su}$, administered in 2 doses, at days 0 and 60 . The graphs show mean \pm SEM SFCs $/ 10^{6}$ PBMCs over time in all ZV recipients (squares and dotted lines) and $\mathrm{HZ} / \mathrm{su}$ recipients (circles and lines). The ordinates are on a natural logarithmic scale. Right column shows responses to VZV and left column to gE ex vivo restimulation. Upper row shows IL-2, middle row shows IFN- $\gamma$, and bottom row shows DP responses. Regression analyses adjusted for baseline and for multiple comparisons showed significantly higher VZV-IL-2 and gEIL-2, gE-IFN- $\gamma$, and DP responses 30 days after the last dose of vaccine in $\mathrm{HZ} / \mathrm{su}$ compared with ZV recipients (FDR-adjusted $P \leq$ $0.01)$. For individual age/treatment groups, see Supplemental Figure 2.
IL-2; VZV stim

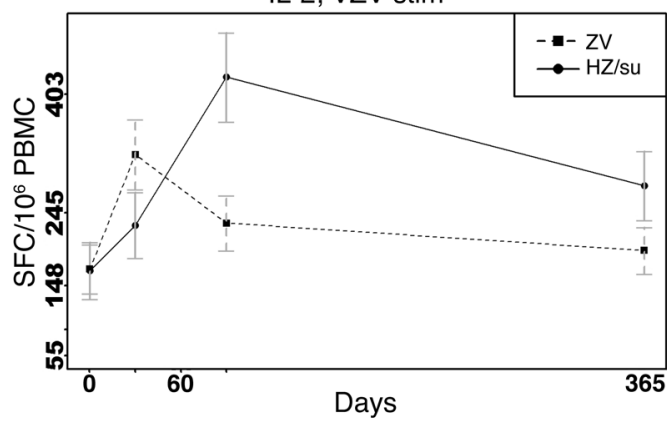

IFN- $\gamma ;$ VZV stim

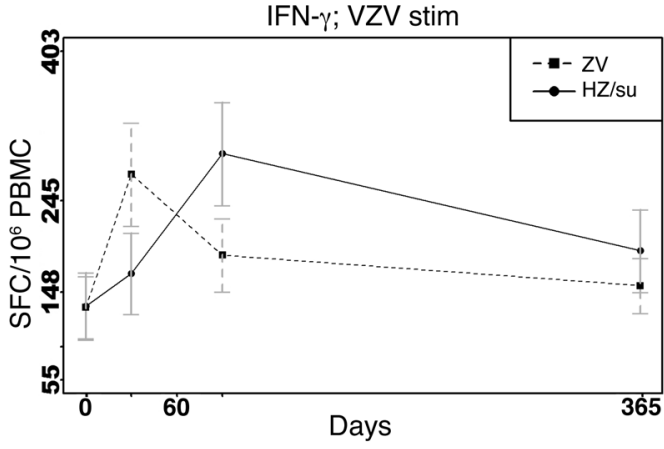

DP; VZV stim

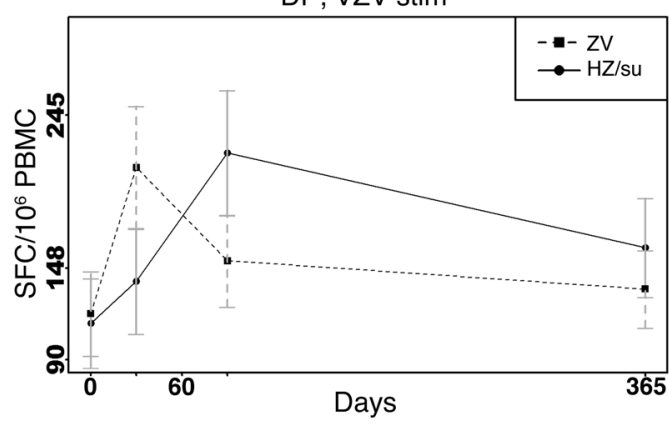

IL-2; gE stim

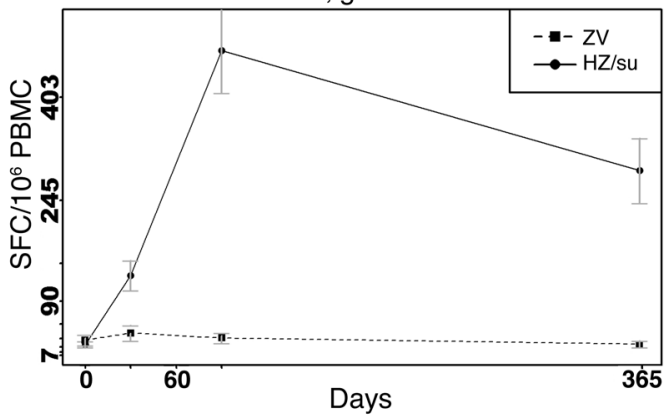

IFN- $\gamma ;$ gE stim

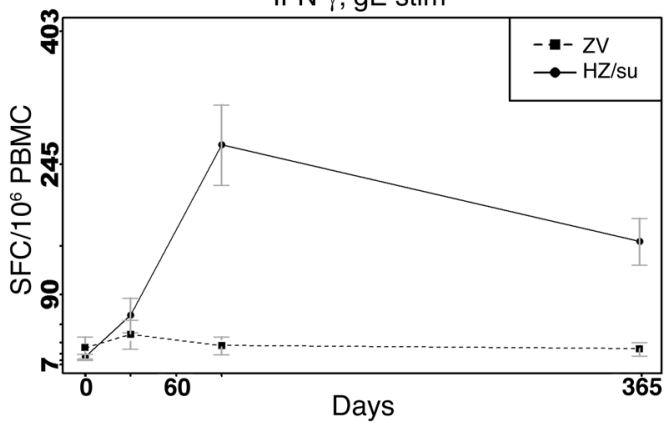

DP; gE stim

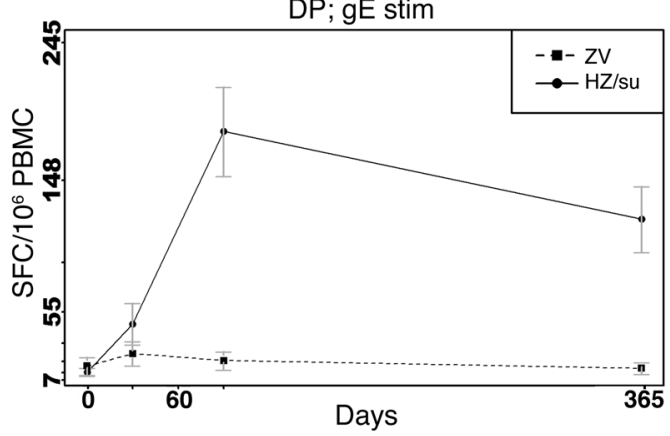


Table 2. $\mathrm{T}$ cell responses to the $\mathrm{HZ}$ vaccines have distinct differentiation profiles

$\begin{array}{lcccc}\text { Differentiation stage } & \text { Mean of ZV/HZ/su results } & \mathbf{9 5 \%} \mathrm{Cl} \text { of the mean } & \boldsymbol{P} \text { value } & \text { FDR-adjusted } \boldsymbol{P} \text { value } \\ \text { Effector CD4 } & 2.07 & 1.56 ; 2.76 & 5.16 \times 10^{-07} & 7.44 \times 10^{-06} \\ \text { Tem cells CD4 } & 0.55 & 0.40 ; 0.74 & 0.0001 & 0.007 \\ \text { Tcm cells CD4 } & 0.76 & 0.63 ; 0.92 & 0.005 & 0.02\end{array}$

Data were derived from 60 participants equally distributed across vaccination and age groups. Means and $95 \% \mathrm{Cl}$ were estimated by logistic regression. Means of less than 1 indicate higher responses in the $\mathrm{HZ} /$ su group, and those greater than 1 indicate higher responses in the ZV group. $P$ values were adjusted for multiple comparisons using FDR correction. Effector CD4, CD4+CD45RO+CCR7-CD27-; Tem cells CD4, CD4+CD45RO+CCR7+CD27; Tcm cells CD4, CD4+CD45RO+CCR7+CD27+.

Baseline VZV-Th1 and gE-Th1 responses had a substantial positive effect on their respective PMR to either vaccine, but age, sex, or prior administration of ZV did not (data not shown). After adjusting for baseline responses, VZV-IL-2 PMR was higher in HZ/ su compared with ZV recipients (FDR-adjusted $P=0.01$; Figure 1), but there were no differences in VZV-IFN- $\gamma$ or VZV-DP responses, which indicated that the type of vaccine had a substantial effect only on VZV-IL-2 among all VZV-Th1 PMR tested. Adjusted gETh1 PMR were significantly higher in HZ/su compared with ZV recipients (FDR $P<0.0001$; Figure 1), indicating that the type of vaccine affected all gE-Th1 PMR.

$T$ cell differentiation in response to $\mathrm{HZ} / \mathrm{su}$ and $\mathrm{ZV}$. In a subset of 60 participants equally distributed between the 2 vaccines and across the 3 age/treatment groups in each vaccine arm (demographics in Supplemental Table 2), we analyzed gE-CD4 $4^{+}$ and $\mathrm{VZV}-\mathrm{CD} 4^{+}$and $\mathrm{gE}-\mathrm{CD} 8^{+}$and $\mathrm{VZV}-\mathrm{CD} 8^{+} \mathrm{T}$ cell differentiation profiles by flow cytometry at PMR. After ex vivo restimulation with gE peptide pools, replication competent VZV, or mock stimulation, we identified $\mathrm{CD}^{+}$and $\mathrm{CD} 8^{+}$central memory $(\mathrm{Tcm})$ cells $\left(\mathrm{CCR} 7^{+} \mathrm{CD} 27^{+} \mathrm{CD} 45 \mathrm{RO} \mathrm{O}^{+}\right)$, effector memory (Tem) cells $\left(\mathrm{CCR} 7{ }^{-} \mathrm{CD} 27^{+} \mathrm{CD} 45 \mathrm{RO}^{+}\right)$, differentiated effector (Teff) cells (CCR7-CD27$\mathrm{CD} 45 \mathrm{RO}^{+}$), intermediate effector (Tei) cells (CCR7$\left.\mathrm{CD}_{27}{ }^{+} \mathrm{CD} 45 \mathrm{RO}^{-}\right)$, and terminally differentiated effector (Ted) cells (CR7 $\left.\mathrm{CD}^{2} 7^{-} \mathrm{CD} 45 \mathrm{RO}^{-}\right)$and confirmed their specificity to the stimulating antigen by IFN- $\gamma$ production (gating strategy shown in Supplemental Figure 3A). It is important to note that both gE peptide pools and replication-competent VZV allow $\mathrm{T}$ cell epitope presentation in the context of MHC classes I and II. The comparison of the baseline-adjusted PMR showed that HZ/su
0.06, respectively; Supplemental Figure 3B).

generated significantly higher gEspecific $\mathrm{CD}^{+}{ }^{+} \mathrm{Tcm}$ cells and Tem cells and lower $\mathrm{CD} 4^{+}$Teff cells compared with the VZV-specific responses generated by ZV (FDR $P<0.05$; Table 2). An alternative sensitivity analysis, in which the effector and memory subsets were expressed as percentages of the gE- and VZV-IFN- $\gamma^{+} \mathrm{T}$ cells, also showed lower $\mathrm{CD} 4^{+}$Teff cells, $\mathrm{CD}^{+}$Tei cells, and $\mathrm{CD} 8^{+}$Tei cells in $\mathrm{HZ} / \mathrm{su}$ compared with ZV recipients (both FDR $P=0.01,0.047$, and

$C D 4^{+}$and $C D 8^{+}$proliferative PMR to $g E$ and $V Z V$. To determine individual contributions of $\mathrm{CD} 4^{+}$and $\mathrm{CD} 8^{+} \mathrm{T}$ cells to the immunologic memory generated by $\mathrm{HZ} / \mathrm{su}$ and $\mathrm{ZV}$, we measured $\mathrm{T}$ cell proliferation by flow cytometry after ex vivo restimulation with gE peptide pools or replication-competent VZV in a subset of 94 participants equally distributed among vaccines $(n=15$ /primary subgroups and 17/boosted; demographic characteristics in Supplemental Table 3; gE-specific results in Figure 2 and VZV-specific results in Supplemental Figure 4). Both HZ/su and ZV recipients showed increases in gE- and VZV-CD4 $4^{+}$and gE- and $\mathrm{CD} 8^{+}$proliferation after vaccination. Peak VZV-CD4 ${ }^{+}$and VZV-CD8 ${ }^{+}$proliferation adjusted for baseline was similar in $\mathrm{HZ} / \mathrm{su}$ and $\mathrm{ZV}$ recipients, but $\mathrm{gE}-\mathrm{CD} 4^{+}$and $\mathrm{gE}-\mathrm{CD} 8^{+}$proliferation was higher in $\mathrm{HZ} / \mathrm{su}$ compared with $\mathrm{ZV}$ recipients (FDR $P<0.001$ ).

We further investigated whether the $\mathrm{CD} 8^{+}$ex vivo proliferation represented $\mathrm{CD} 8^{+}$memory formation in response to vaccination or a bystander effect of the strong $\mathrm{CD} 4^{+}$responses to vaccination. We and others have previously demonstrated that ELISpot measures primarily CD4 ${ }^{+} \mathrm{T}$ cell responses $(27,28)$. We

\section{Table 3. Comparative effects of ZV and HZ/su on baseline-adjusted PMR T cell profiles}

\begin{tabular}{|c|c|c|c|c|c|}
\hline Specificity & Subset (\% of parent) & Mean of $\mathrm{ZV} / \mathrm{HZ} /$ su results & $95 \% \mathrm{Cl}$ & $P$ value & FDR-adjusted $P$ value \\
\hline \multirow[t]{3}{*}{ VZV } & $\mathrm{CD}^{+} \mathrm{FOXP3}^{+} \mathrm{CD}_{25}{ }^{+}$ & 0.85 & $0.79,0.92$ & 0.0003 & 0.01 \\
\hline & $\mathrm{CD}^{+} \mathrm{CD}^{-} 7^{-}$ & 0.76 & $0.65,0.88$ & 0.001 & 0.02 \\
\hline & $\mathrm{CD}^{+} \mathrm{CD}^{-107 \mathrm{a}^{+}}$ & 1.43 & $1.09,1.89$ & 0.01 & 0.17 \\
\hline \multirow[t]{10}{*}{$\mathrm{gE}$} & CD4 ${ }^{+}$TNF- $\alpha^{+}$ & 0.38 & $0.30,0.47$ & $<0.0001$ & $<0.0001$ \\
\hline & $\mathrm{CD}^{+} \mathrm{LAG3}^{+}$ & 0.40 & $0.31,0.51$ & $<0.0001$ & $<0.0001$ \\
\hline & $\mathrm{CD}^{+}{ }^{+} \mathrm{CXCR}^{+} \mathrm{LAC3}^{+}$ & 0.44 & $0.36,0.55$ & $<0.0001$ & $<0.0001$ \\
\hline & $\mathrm{CDB}^{+} \mathrm{TIM}^{+}$ & 0.76 & $0.70,0.82$ & $<0.0001$ & $<0.0001$ \\
\hline & $\mathrm{CD}^{+}{ }^{+} \mathrm{CXCR}^{+} \mathrm{LAC3}^{+}$ & 0.64 & $0.56,0.74$ & $<0.0001$ & $<0.0001$ \\
\hline & $\mathrm{CD}^{+} \mathrm{LAG3}^{+} \mathrm{TIM}^{+}$ & 0.47 & $0.37,0.60$ & $<0.0001$ & $<0.0001$ \\
\hline & CD4 ${ }^{+}$TNF- $\alpha^{+}$IFN $-\gamma^{+}$ & 0.25 & $0.16,0.38$ & $<0.0001$ & $<0.0001$ \\
\hline & $\mathrm{CD}^{+} \mathrm{CD} 107 \mathrm{a}^{+} \mathrm{TNF}-\alpha^{+}$ & 0.37 & $0.27,0.52$ & $<0.0001$ & $<0.0001$ \\
\hline & $\mathrm{CD}^{+} \mathrm{LAC3}^{+}$ & 0.69 & $0.60,0.79$ & $<0.0001$ & $<0.0001$ \\
\hline & $\mathrm{CD}^{+}{ }^{+} D 017 \mathrm{a}^{+} \mathrm{IFN}-\gamma^{+} \mathrm{TNF}-\alpha^{+}$ & 0.26 & $0.16,0.43$ & $<0.0001$ & $<0.0001$ \\
\hline
\end{tabular}

Data were derived from 60 participants equally distributed between groups. Means and $95 \% \mathrm{Cl}$ were estimated by logistic regression for the ratios of $\mathrm{ZV} / \mathrm{HZ}$ su results. Means less than 1 indicate higher responses in the $\mathrm{HZ} / \mathrm{su}$ group, and means greater than 1 indicate higher responses in the $Z V$ group. $P$ values were adjusted for multiple comparisons using FDR correction. Shown are all the significant differences in VZV-specific responses and $10 \mathrm{gE}$-specific responses with the largest estimates. 


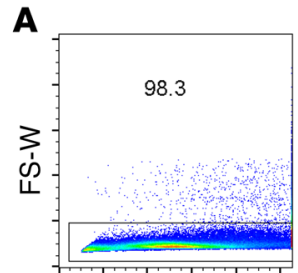

FS-A

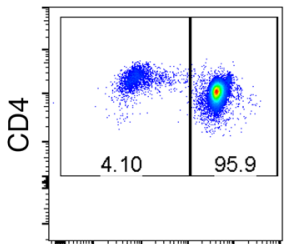

Cell Trace

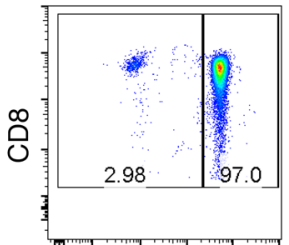

Cell Trace

Day 0

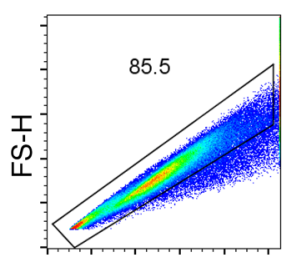

FS-A
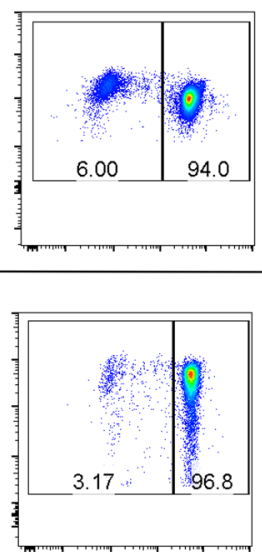

Day 30

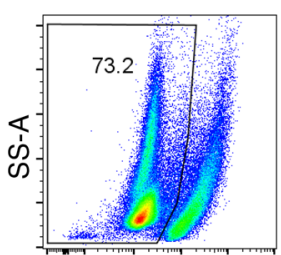

Live/dead
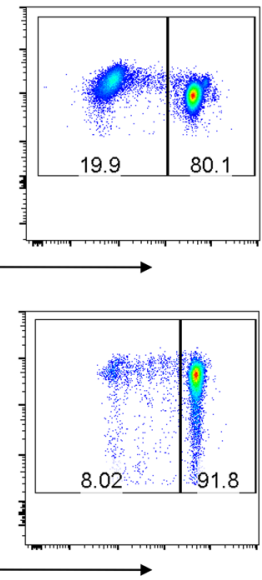

Day 90

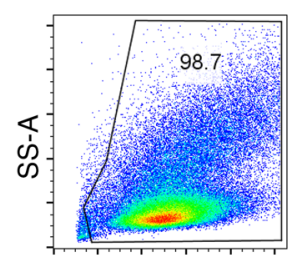

FS-A

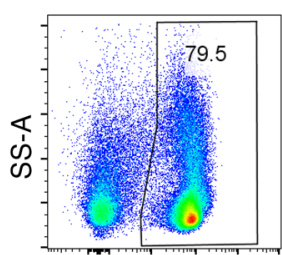

CD3

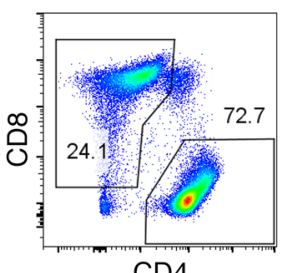

CD4

B

CD4 proliferation

CD8 proliferation
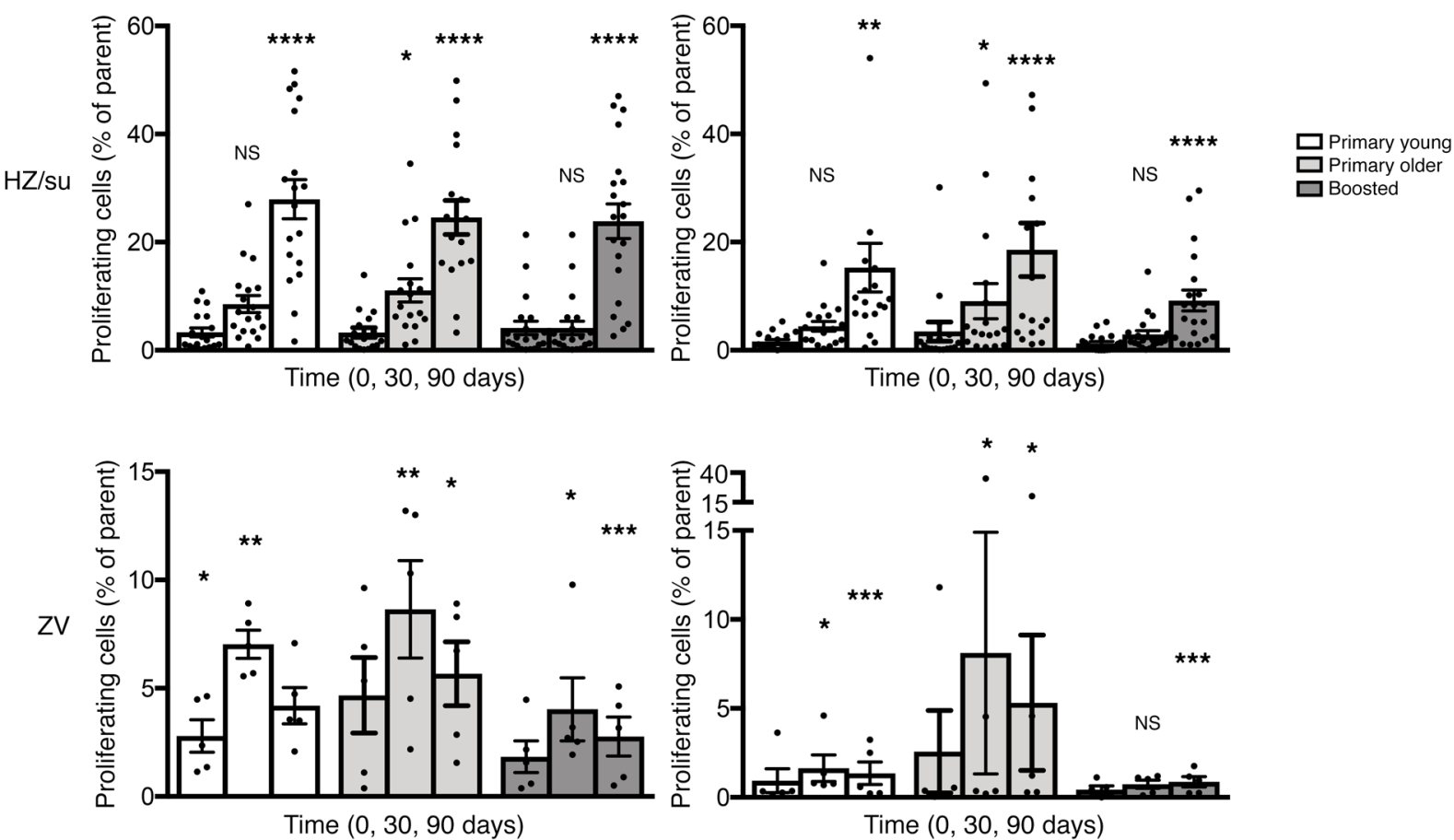

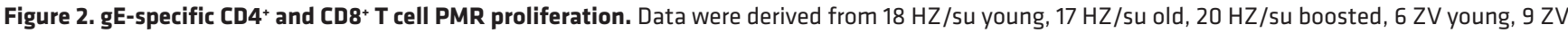
old, and 9 ZV boosted. (A) Gating strategy. (B) Summary of proliferation in each age and treatment group. Percentage of proliferating cells of the parent indicates that proliferating $\mathrm{CD} 4^{+}$or $\mathrm{CD} 8^{+} \mathrm{T}$ cells are expressed as a percentage of the total $\mathrm{CD} 4^{+}$or $\mathrm{CD} 8^{+} \mathrm{T}$ cell parent population, as appropriate. Asterisks show the significance of differences compared with baseline using RMANOVA adjusted for multiple comparisons. ${ }^{*} P<0.05$ and $>0.01$, ${ }^{*} P<0.01$ and $>$ $0.001,{ }^{* *} P<0.001,{ }^{* * *} P<0.0001$. In addition, baseline-adjusted PMR regression analysis between vaccine groups had FDR-adjusted $P<0.0001$. FS-A, forward scatter area; FS-H, forward scatter height; FS-W, forward scatter width; SS-A, side scatter area. 
Table 4. Results of the mediation analysis of the PMR IL-2 on the persistent persistence of the Th1 responses to vaccination

Estimate of the IL-2 PMR-mediated effect (ACME) $\quad 95 \% \mathrm{Cl} \quad P$ value or of the vaccine direct effect (ADE)

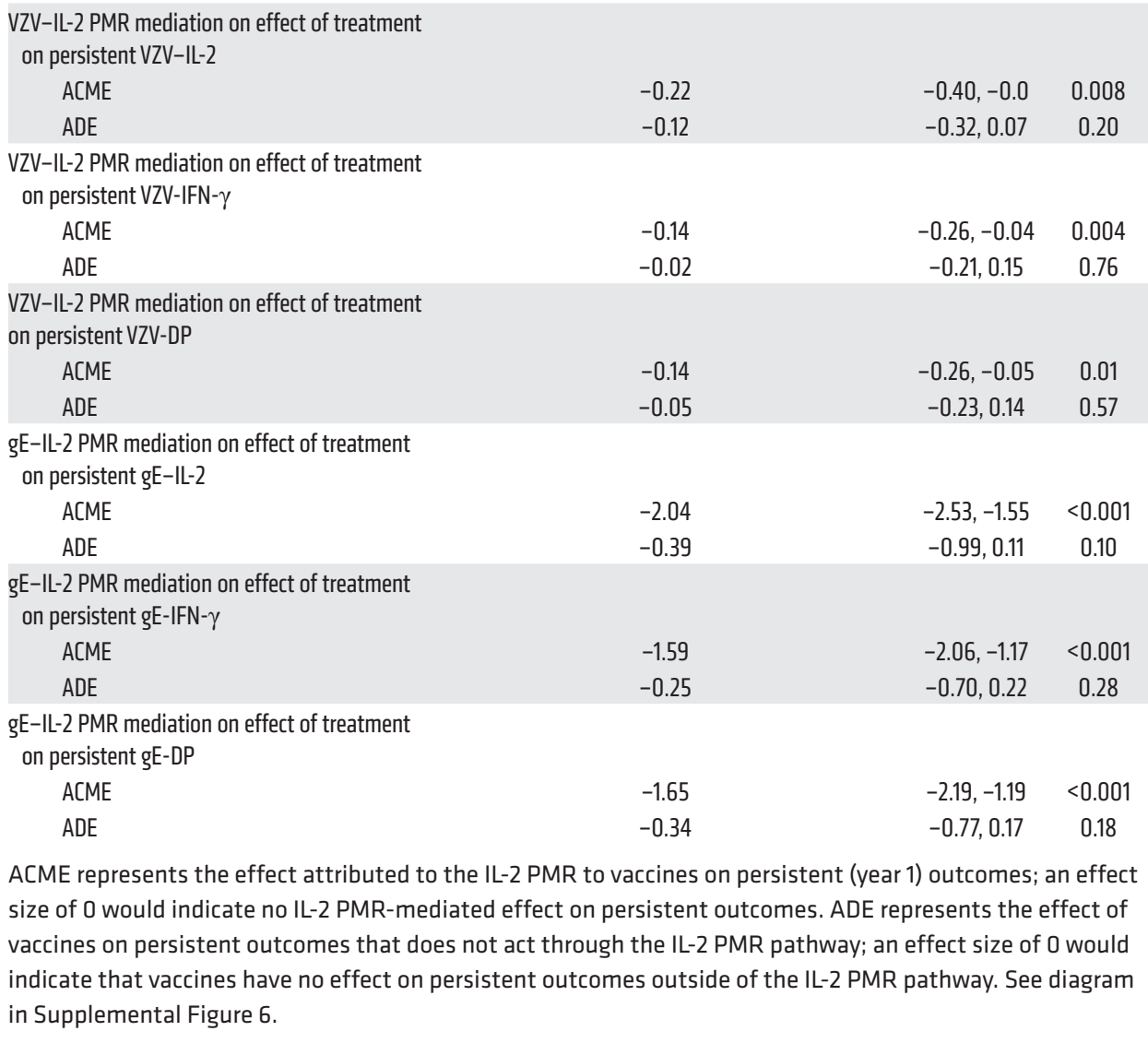

or $\mathrm{CXCR}^{+}$) clustered together with VZV-specific Tregs (CD25+ $5^{+}$CD127-, and/or $\mathrm{FOXP3}^{+}$) and Tcheck $\left(\mathrm{LAG}^{+}\right.$ and $\left.\mathrm{TIM}^{+}\right)$. gE-specific Teff cells and Tcheck also clustered together.

Regression analyses of PMR adjusted for baseline showed that, compared with $\mathrm{ZV}, \mathrm{HZ} / \mathrm{su}$ recipients had significantly higher $\mathrm{CD}^{+}$ VZV-Treg, CD8 ${ }^{+}$VZV-Tcheck and $\mathrm{CD}^{+}$and $\mathrm{CD}^{+}$gE-Teff cells and gE-Tcheck (Table 3). CD8 ${ }^{+}$CD107a ${ }^{+}$ cytolytic VZV-Teff cells were significantly higher $(P=0.01)$ in $\mathrm{ZV}$ compared with $\mathrm{HZ} / \mathrm{su}$ recipients, but only before adjustment for multiple comparisons. Age, sex, and booster status did not affect the differential effect of the 2 vaccines on immune responses. However, compared with the primary $\mathrm{HZ} /$ su groups, the boosted group had lower $\mathrm{CD}^{+}$and/or $\mathrm{CD}^{+} \mathrm{VZV}$-Teff cells, VZV-Tregs, and VZV-Tcheck and $\mathrm{CD}^{+}$gE-Tcheck (Supplemental Table 5). This was not observed in $\mathrm{ZV}$ recipients.

Aggregate results highlighting the differences between CMI responses to $\mathrm{HZ} / \mathrm{su}$ and to $\mathrm{ZV}$. To select the best candidates for immune correlates with the superior efficacy of $\mathrm{HZ} / \mathrm{su}$ compared with $\mathrm{ZV}$, we built a forest plot of the top parameters that differentiated between vaccine responses (Figure 5). Responses that were high-

used this property to determine whether $\mathrm{CD} 8^{+} \mathrm{T}$ cell proliferation depended on IL-2 production by $\mathrm{CD}^{+} \mathrm{T}$ cells. The data did not show significant associations between PMR gE-IL-2 SFCs and gE$\mathrm{CD}^{+}$proliferation $(P=0.13$; Supplemental Figure 5$)$. In contrast, gE-IL-2 SFC PMR significantly correlated with gE-CD4 ${ }^{+}$proliferation $(P<0.0001$; Supplemental Figure 5$)$. This suggested that $\mathrm{CD} 8^{+}$proliferation at $\mathrm{PMR}$ represented $\mathrm{CD} 8^{+}$memory responses that were independent of the stimulation provided by $\mathrm{CD}^{+}$via ex vivo IL-2 secretion.

Flow cytometric analysis of $C D 4^{+}$and $C D 8^{+} g E-T$ cell and $\mathrm{VZV}-$ $T$ cell profiles at $P M R$. Responses generated by the vaccines were also characterized using functional Teff cells, Tregs, and immunologic checkpoint (Tcheck) markers after gE, VZV, and mock ex vivo restimulation in a subset of $30 \mathrm{HZ} / \mathrm{su}$ and $30 \mathrm{ZV}$ recipients equally distributed across the 3 age and immunization subgroups (demographics shown in Supplemental Table 2). Of the 126 flow parameters measured (Supplemental Table 4), 59 parameters were eliminated because the median ratio of gE- or VZV-stimulated divided by the mock-stimulated responses were less than 1.1 in both vaccine groups. Figures 3 and 4 show heatmaps of unsupervised clusters of the subsets remaining in the analysis. The VZVspecific $\mathrm{CD}^{+}$and $\mathrm{CD} 8^{+}$Teff cells (IFN- $\gamma^{+}, \mathrm{TNF}-\alpha^{+}, \mathrm{CD} 107 \mathrm{a}^{+}$, and/ er in $\mathrm{ZV}$ compared with $\mathrm{HZ} / \mathrm{su}$ recipients included VZV-CD4 ${ }^{+}$ Teff cells and VZV-CD8 ${ }^{+}$CTL PMR. HZ/su recipients had higher gE-Th1, gE-Teff cells, gE-Tcheck, and gE-CD4 ${ }^{+}$and gE-CD8 ${ }^{+}$ proliferative PMR and gE-Th1 persistent responses, which were consistent with the higher amount of gE in HZ/su compared with ZV. However, HZ/su also had higher VZV-IL-2 and VZV-CD4+ Treg PMR and VZV-IL-2 persistent responses at year 1 compared with $\mathrm{ZV}$ recipients.

Post hoc mediation analysis of the difference in persistence of Th1 responses between the 2 vaccines. The difference in persistence of VZV-Th1 and gE-Th1 responses at 1 year between the 2 vaccines was analyzed by multivariate regression, including the factors that had a significant (Table 4) effect on persistence in univariate analyses: vaccine type, baseline Th1 responses, and PMR Th1. The multivariate analysis showed that VZV-Th1 baseline and PMR, but not vaccine type, had independent significant (Table 4) effects on VZV-Th1 persistence, whereas vaccine type and gETh1 PMR, but not baseline gE-Th1, had independent effects on gE-Th1 persistence (data not shown). Upon noting that IL-2 PMR represented the common denominator among factors with independent effects on persistence of both gE-Th1 and VZV-Th1, we hypothesized that the VZV-IL-2 and gE-IL-2 PMR after vaccina- 


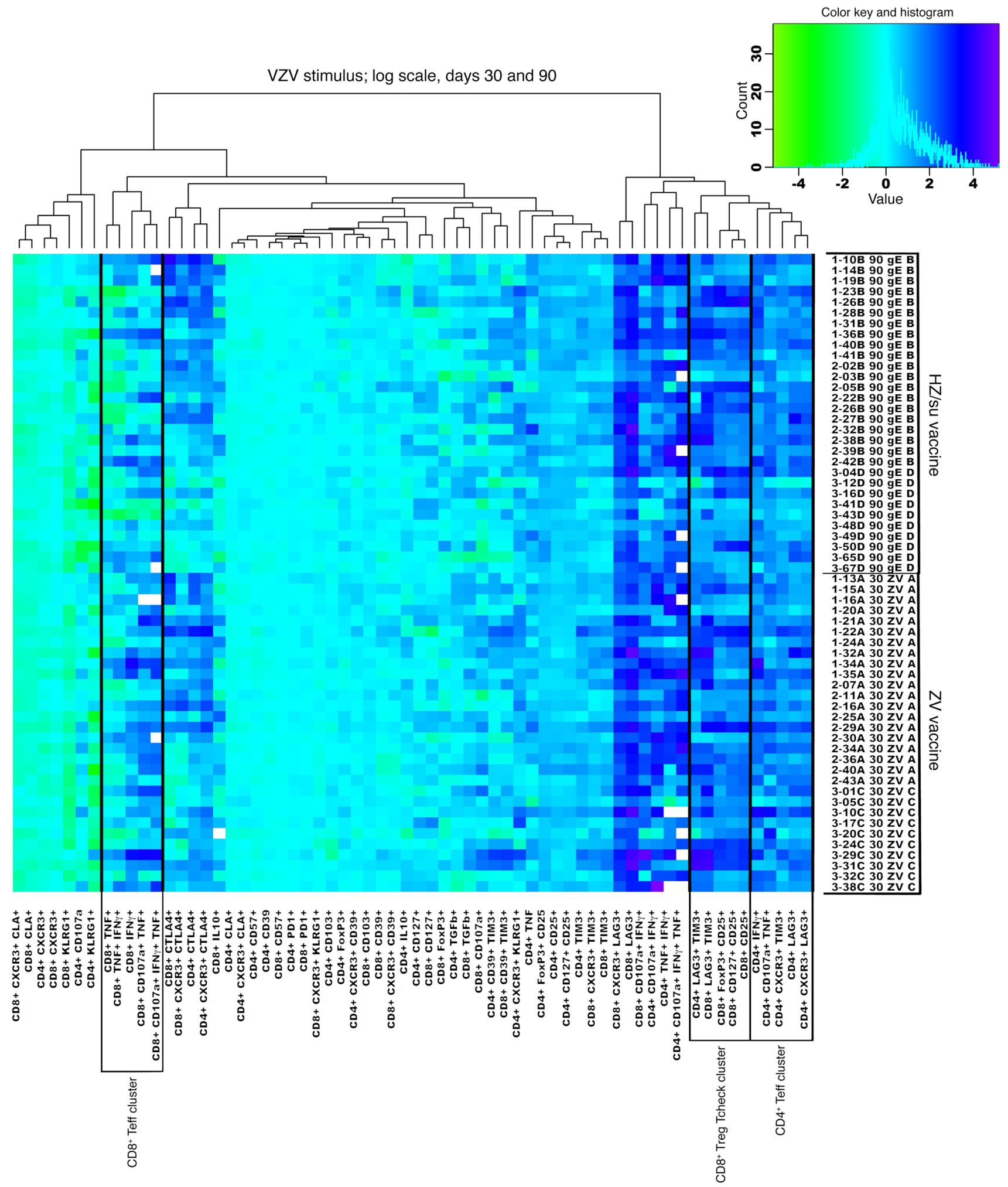

Figure 3. Conventional and regulatory $\mathrm{T}$ cell responses in $\mathrm{HZ} / \mathbf{s u}$ and $\mathrm{ZV}$ recipients at PMR. PMR was day 30 for $\mathrm{ZV}$ and 90 for $\mathrm{HZ} / \mathrm{su}$ recipients. Data were derived from 60 participants equally distributed across vaccination and age groups. The heatmap T cell responses to VZV ex vivo restimulation were grouped by unbiased hierarchical clustering. Each column represents a T cell subset and each row an individual participant. A, ZV primary group; B, HZ/su primary group; C, ZV boosted group; D, HZ/su boosted group. The rectangles identify T cell clusters. 
Color key and histogram

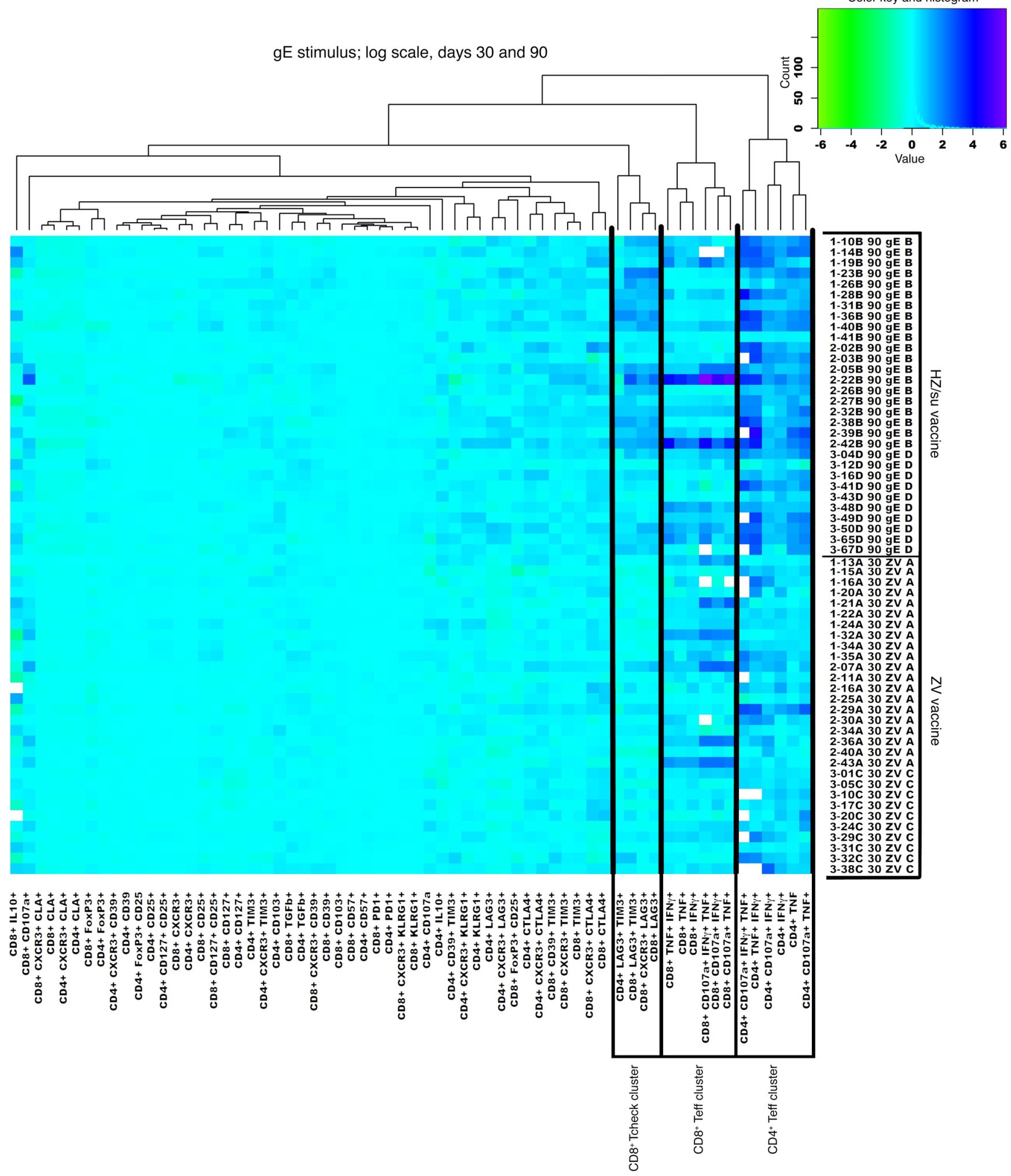

Figure 4. Conventional and regulatory $\mathrm{T}$ cell responses in $\mathrm{HZ} / \mathbf{s u}$ and $\mathbf{Z V}$ recipients at PMR. PMR was day 30 for $Z V$ and 90 for $\mathrm{HZ} / \mathrm{su}$ recipients. Data were derived from 60 participants equally distributed across vaccination and age groups. The heatmap $T$ cell responses to VZV ex vivo restimulation were grouped by unbiased hierarchical clustering. Each column represents a T cell subset and each row an individual participant. A, ZV primary group; B, HZ/su primary group; C, ZV boosted group; D, HZ/su boosted group. The rectangles identify T cell clusters. 


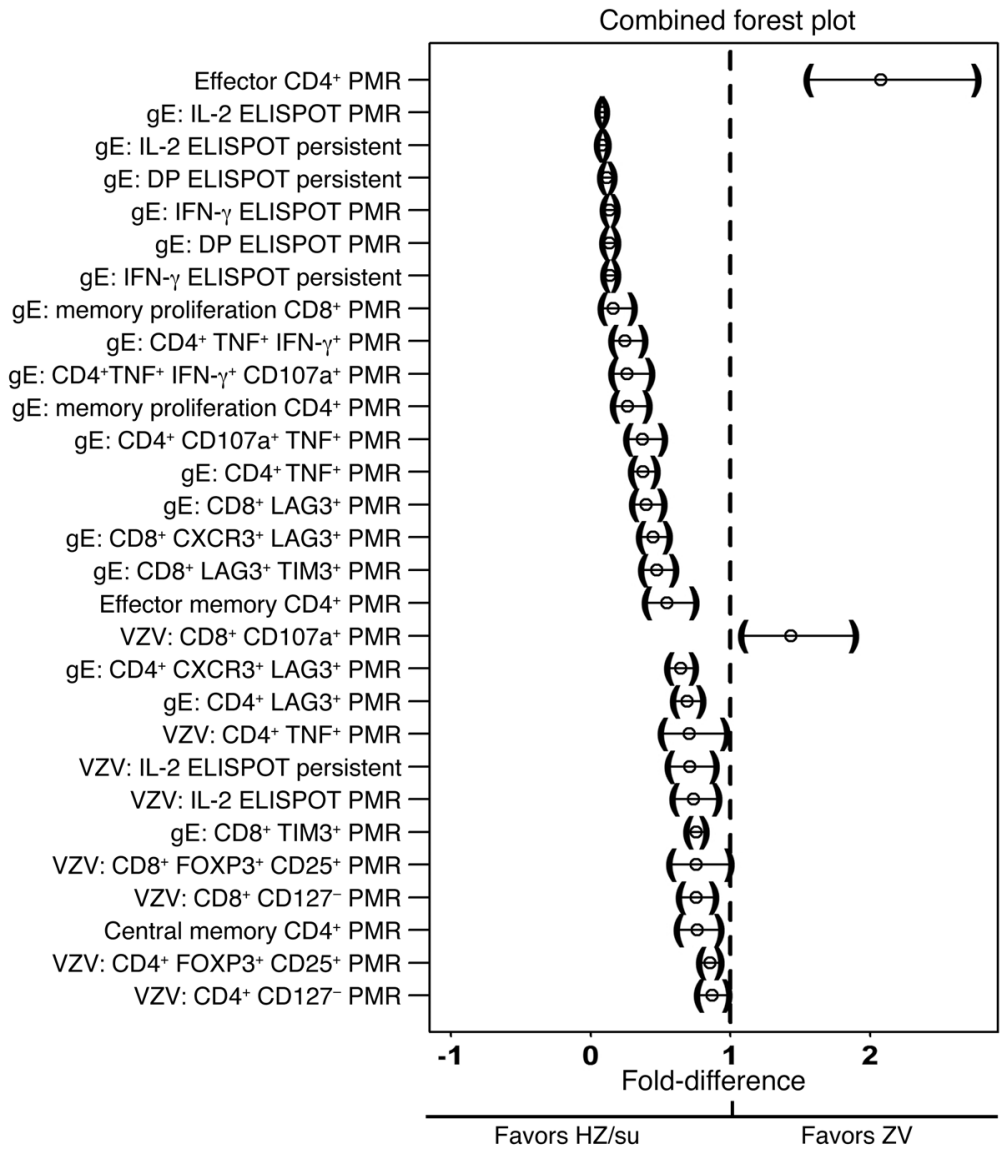

Figure 5. Hierarchical presentation of $\mathrm{T}$ cell responses that significantly differentiate the 2 vaccines. Data were derived from 158 participants for ELISpot, 94 for proliferation, and 60 for T cell differentiation and functional PMR. The plot shows means estimated for the fold differences of $\mathrm{ZV} / \mathrm{HZ} /$ su results and $95 \% \mathrm{CI}$ for significantly different parameters $(95 \% \mathrm{Cl}$ does not overlap the null effect, i.e., equivalence, indicated by the dotted vertical line). All other parameters are shown in Supplemental Figure 7. The stimulant and T cell responses are indicated on the coordinate. Means of less than 1 indicate higher responses in the $\mathrm{HZ} / \mathrm{su}$ group, and those greater than 1 indicate higher responses in the ZV group.

tion represented the immunologic mechanism necessary and sufficient for VZV-Th1 and gE-Th1 persistence after vaccination. To test this new hypothesis, we performed post hoc mediation analyses (Table 4). The mediation analysis measured the average controlled mediated effect (ACME), which represents the estimated effect of the vaccines on the persistence of Th1 responses attributed to their effects on IL-2 PMR, and the average direct effect (ADE), which represents the estimated effect of the vaccines on persistence of Th1 responses that does not act through the IL-2 PMR pathway (Supplemental Figure 6). The data showed nonsignificant ADE $(P>0.1)$ and highly significant ACME $(P \leq 0.01)$ for both gE-Th1- and VZV-Th1 one-year responses, indicating that IL-2 PMR mediated the effect of vaccines on the persistence of Th1 responses to vaccination.

\section{Discussion}

The primary objective of this study was to identify immune responses that may explain the superior protection against $\mathrm{HZ}$ conferred by $\mathrm{HZ} /$ su compared with $\mathrm{ZV}$. Immune responses that clearly distinguished the 2 vaccines were the higher gE- and VZV-specific memory Th1 responses generated by $\mathrm{HZ} / \mathrm{su}$, including peak $\mathrm{CD} 4^{+} \mathrm{Tcm}$ and $\mathrm{Tem}$ percentages, gE-IL-2 and VZV-IL-2 SFCs, and CD4 ${ }^{+}$ and $\mathrm{CD} 8^{+} \mathrm{gE}$ memory measured by proliferation. The predominance of memory responses in $\mathrm{HZ} /$ su recipients may explain the sustained protection against $\mathrm{HZ}$ of $87 \%$ or more up to 4 years after HZ/su administration compared with approximately $40 \%$ protection by ZV after a similar interval $(12,16,17,29)$. Higher VZV-Treg and gE-Tcheck percentages at PMR in HZ/ su compared with $\mathrm{ZV}$ recipients are also probably related to the higher memory responses in $\mathrm{HZ} / \mathrm{su}$. Tregs and Tcheck may play a role in Th1 differentiation by directing the immune response from effector to memory (30-32). Alternatively, they may signal that Teff cells are being quenched. In contrast with $\mathrm{HZ} / \mathrm{su}$, the immune response to $\mathrm{ZV}$ was characterized by higher VZV-CD4 ${ }^{+}$and VZV-CD8 ${ }^{+}$effectors at PMR. This may be due to the nature of this live virus vaccine, which includes an agent capable of multiple cycles of replications that sustain the Teff cells for a longer period. This is in agreement with the findings of our previous study in which we used VZV DNAemia after $\mathrm{ZV}$ administration as an indicator of vaccine viral replication and found that DNAemia positively correlated with longer persistence of VZV-Teff cells in the circulation and with delayed increase of Th1 memory responses after ZV (33).

The very low or absent gE-Th1 responses before $\mathrm{HZ} /$ su administration, even in those who had received ZV 5 or more years before entering the study, suggest that $\mathrm{T}$ cell responses to $\mathrm{gE}$ are not dominant after wild or attenuated VZV infection and that some individuals do not mount responses to gE or lose these responses over time. In fact, after the first dose of $\mathrm{HZ} / \mathrm{su}$, responses to gE were very low, and responses to VZV were lower than those of $\mathrm{ZV}$ recipients. This finding is in agreement with previously published data showing gE-specific $\mathrm{CD}^{+} \mathrm{Th} 1$ responses by flow cytometry in only $20 \%$ of vaccinees after the first dose of HZ/su (34). Sei et al. (35) also showed that other VZV gene products, including IE 63, IE 62, gB, and ORF 9 , were targeted more frequently than $\mathrm{gE}$ by $\mathrm{CD} 4^{+}$and $\mathrm{CD} 8^{+} \mathrm{T}$ cells in response to $\mathrm{ZV}$ administration. Taken together, these observations underscore 2 important points: (a) the second dose of $\mathrm{HZ} / \mathrm{su}$ is essential for immunogenicity and efficacy of this vaccine (this difference is not explained by $\mathrm{ZV}$ being administered as a single dose, since providing 2 doses of $\mathrm{ZV}$ does not significantly alter the immune response) $(36,37)$; and (b) biologically significant gE-Th1 responder $\mathrm{T}$ cells may arise from naive cells. Whether drawing responses from the naive $\mathrm{T}$ cell pool may be advantageous for the host because these cells have undergone fewer cycles of replication than memory cells and/or are less exhausted and, therefore, may generate longer lasting memory or more efficient killing is not known. Akondy et al. showed that ZV also draws Th1 responders from the naive $\mathrm{T}$ cell pool, but those responders died quickly and did not contribute to persistent immunity (38). The role of de 
novo responses to $\mathrm{HZ} / \mathrm{su}$ in its efficacy warrants further investigation because this factor may have important implications for the design of other vaccines for older adults.

The gE-IL-2 and VZV-IL-2 PMR to HZ/su and ZV not only independently contributed to the persistence of Th1 responses after vaccination, but also mediated the effect of the vaccines on persistent Th1, indicating that IL-2 PMR was necessary for the persistence of Th1 responses after vaccination. Our findings contrast with a previous study in which persistence of IFN- $\gamma$ responses to $\mathrm{ZV}$ was not predicted by the magnitude of the VZV-IFN- $\gamma$ PMR (39). The difference underscores the importance of IL-2 as a predictor of immunogenicity. Currently, there is no mechanistic immune correlate of protection conferred by ZV or HZ/su. gE-IL-2 and/or VZV-IL-2 PMR is a strong candidate to fill this gap, which we are planning to verify in studies in which $\mathrm{HZ}$ is an end point, such as in immune-compromised hosts.

$\mathrm{CD}^{+} \mathrm{T}$ cells have a prominent role in protection against herpesviruses (40). Increased VZV-CD8 ${ }^{+}$Teff cells have been described during convalescence from chicken pox and $\mathrm{HZ}$ and after exogenous exposure to VZV or reactivation of VZV (41-43). gE-specific CD8 ${ }^{+}$Teff cell responses to $\mathrm{HZ} /$ su have not been previously demonstrated in humans, although the QS21 component of $\mathrm{ASO1}_{\mathrm{B}}$ is known to promote antigen crosspresentation by dendritic cells $(44,45) . \mathrm{CD}^{+} \mathrm{T}$ cell responses to antigens coformulated with $\mathrm{ASO}_{\mathrm{B}}$ were observed in mouse vaccination models and in in vitro human studies $(44,45)$. Here, we demonstrated that HZ/su generated gE- and VZV-specific $\mathrm{CD}^{+}{ }^{+} \mathrm{T}$ cell-proliferative PMR independent of CD $4^{+} \mathrm{T}$ cell IL-2 production. Furthermore, sorted proliferating $\mathrm{CD}^{+} \mathrm{T}$ cells from $\mathrm{HZ} / \mathrm{su}$ recipients respond with IFN- $\gamma$ and/ or IL-2 production when stimulated by autologous lymphoblastoid cells infected with $\mathrm{gE}$-containing vaccinia virus vectors and when restimulated with $\mathrm{gE}$ peptide pools as previously described (46, 47). We also showed that gE- and VZV-specific CD8 ${ }^{+} \mathrm{T}$ cells generated by HZ/su produced fewer Th1 cytokines and cytotoxicity markers compared with $\mathrm{CD} 8^{+} \mathrm{T}$ cells generated by $\mathrm{ZV}$. In contrast, $\mathrm{HZ} /$ su generated higher $\mathrm{CD} 8^{+}$Tcheck and Treg PMR. The upregulation of Tcheck may quench the Teff cell function of CD8 ${ }^{+} \mathrm{T}$ cells, which explains the difficulty in demonstrating gE-specific CD8 ${ }^{+}$ Teff cell responses after HZ/su administration. Alternatively, the $\mathrm{CD}^{+} \mathrm{T}$ cells generated in response to HZ/su may use cytotoxicity mediators that we did not study.

Our study was the first, to our knowledge, to compare immune responses to $\mathrm{HZ} / \mathrm{su}$ between older adults who previously received ZV or did not (48). The FluoroSpot responses of individuals immunized with $\mathrm{HZ} / \mathrm{su}$ were similar regardless of prior $\mathrm{ZV}$ administration, which was confirmed by a recent publication (49). However, some Teff cell and Tcheck PMR were lower in HZ/su recipients who had prior ZV. While our study was powered for the FluoroSpot outcome measure, the Teff cell and Tcheck studies were part of an exploratory analysis and need to be confirmed.

The immunologic responses to $\mathrm{HZ} /$ su may also provide insight into the immunologic mechanism or mechanisms responsible for preventing HZ. Latent VZV is present only in sensory neurons of dorsal root ganglia (50). Current models suggest that latency is maintained either by (a) VZV T cells that synapse with latently infected neurons to provide signals required to maintain latency or (b) VZV CMI, which limits replication of reactivated virus and therefore pre- vents symptomatic disease, for which there is growing evidence (5154). The second model is supported by our findings, since latently infected neurons do not express $\mathrm{gE}$, and yet this remarkably efficacious vaccine relies on memory $\mathrm{gE}$ responses for its protective effect (54-56). This implies that protection against HZ is conferred by surveillance for and rapid resolution of sporadic VZV reactivation.

There are limitations in this study. These include the small sample size, especially for certain measures of VZV-specific responses, and the inability to relate the immune responses to clinical end points.

The high efficacy of HZ/su is exceptional among vaccines given to older adults and among investigational vaccines against herpesviruses. Compared with $\mathrm{ZV}, \mathrm{HZ} / \mathrm{su}$ is distinguished by robust and persistent memory responses. The $\mathrm{ASO}_{\mathrm{B}}$ adjuvant is critical for the magnitude of the Th response to $\mathrm{HZ} / \mathrm{su}$, as previously shown $(23,34,57)$, and probably plays a role in its persistence. $\mathrm{ASO}_{\mathrm{B}}$ may be of value with other subunit antigens in older adults and in other herpesvirus vaccines.

\section{Methods}

Study design. This study enrolled 160 participants in good health except for treated chronic illnesses typical of the age of the vaccinees. All had prior varicella or had resided in the US at least 30 years; none had prior HZ. Exclusions from the study were immune suppression and recent administration of blood products or other vaccines. Arms A and B (Supplemental Figure 1 and Supplemental Table 1), which contained 90 total participants who had not previously had ZV, were randomly assigned to receive either $\mathrm{ZV}$ followed by placebo or 2 doses of $\mathrm{HZ} / \mathrm{su}$, at days $\mathrm{O}$ and 60 . Arms $\mathrm{A}$ and $\mathrm{B}$ were further stratified by age (50-59 yoa, $n=22$; or 70-85 yoa, $n=23$ ). Arms $\mathrm{C}$ and $\mathrm{D}$ contained an additional 70 participants who were $70-85$ yoa and had received $\mathrm{ZV}$ 5 or more years previously. These were randomly assigned to receive either an additional dose of ZV followed by placebo (arm C) or 2 doses of $\mathrm{HZ} / \mathrm{su}(\mathrm{arm} \mathrm{D})$. Participants were blinded to all vaccinations. Blood was obtained for immunologic assessment on days 0, 30, 90, and 356 from all participants. Additional blood was drawn for arm A on day 7 and for arm B on days 7 and 67. PBMCs, plasma, and serum were cryopreserved within 4 hours of acquisition $(58,59)$.

Flow cytometric enumeration of VZV- and gE-specific T cell subsets. Thawed PBMCs were cultured as above at $2.5 \times 10^{6}$ cells $/ \mathrm{ml}$ in growth medium in the presence of infectious VZV $(60,000 \mathrm{PFU} / \mathrm{ml})$, gE peptide pools as above $(2.5 \mu \mathrm{g} / \mathrm{ml})$, or mock stimulation. CD28 (Mabtech FSP-0102-10) and CD49D (BD 340976) mAbs were added at $1 \mu \mathrm{g} / \mathrm{ml}$. Brefeldin A (MilliporeSigma, $5 \mu \mathrm{g} / \mathrm{ml}$ ), Monensin (MilliporeSigma, 5 $\mu \mathrm{g} / \mathrm{ml}$ ), and anti-CD107a (clone H4A3; BD 328609) were added for the last 16 hours. gE-stimulated and mock-stimulated cells were incubated for 18 hours, while wells with infectious VZV were incubated for 42 hours. At the end of the incubation, PBMCs were washed and incubated with Zombie Yellow Viability Stain (BioLegend). PBMCs were then washed in 1\% BSA (MilliporeSigma) in PBS (Mediatech) (stain buffer), divided into 3 panels, and incubated with Abs against the following markers: CD3 (Ax700; clone UCHT1; BD 557943; all panels), CD4 (PC5.5; clone 13B8.2; Beckman Coulter B16491; all panels), CD45RO (PE-CF594; clone UCHL1; BD 562327; panel 1), CCR7 (APC; clone 3D12; BD 353213; panel 1), CD27 (PE-Cy7; clone M-T271; BD 302837; panel 1), CD103 (PE; clone Ber-ACT8; BioLegend 350205; panel 1), CD57 (FITC; clone NK-1; BD 561906; panel 2), CD127 (PE- 
CF594; clone HIL-7R-M21; BD 562397; panel 2), CD25 (APC-Cy7; clone M-A251; BD 557753; panel 2), PD1 (BV421; clone EH12.2H7; BioLegend 329919; panel 2), CLA (FITC; clone HECA-452; BD 561987; panel 3), LAG3 (PE; clone 3DS223H; eBioscience 12-2239-41; panel 3), TIM3 (PE-CF594; clone 7D3; BD 565561; panel 3), CD39 (PE-Cy7; clone A1; BioLegend 328211; panel 3), CTLA4 (APC; clone L3D10; BioLegend 349907; panel 3), CXCR3 (APC-Cy7; clone G025H7; BioLegend 353721; panel 3), and KLRG1 (BV421; clone 2F1/KLRG1; BioLegend 138413; panel 3). Intracellular staining was performed with Abs against IL-10 (PE-Cy7; clone JES3-9D7; BioLegend 501419; panel 2), TGF- $\beta$ (APC; clone TW4-2F8; BioLegend 349607; panel 2), TNF- $\alpha$ (APC-Cy7; clone MAb11; BioLegend 502943; panel 1), IFN- $\gamma$ (BV421; clone B27; BD 502531; panel 1), and FoxP3 (PE; clone 259D/ C7; BD 560082; panel 2) as appropriate. Unbound Abs were removed by washing with staining buffer and were fixed in $2 \%$ paraformaldehyde (Electron Microscopy Sciences) in PBS, and 200,000 or more events were acquired with the Gallios (Beckman Coulter) instrument and analyzed using FlowJo (Tree Star) software. The gating strategies are shown in Supplemental Figure 8. Supplemental Figure 9 shows the Treg specificity of the FOXP $3^{+} \mathrm{CD} 25^{+}$marker combination as verified during staining optimization assays.

$T$ cell proliferation measured by flow cytometry. Thawed PBMCs stained with CellTrace Violet (BioLegend) were cultured in the presence of infectious VZV, gE peptide pools as above, or mock stimulation for 5 days at $10^{6} \mathrm{PBMCs} / \mathrm{ml}$ as above. On day 3, $3.3 \mathrm{IU} / \mathrm{ml}$ rhIL-2 (R\&D Systems) was added to mock and VZV wells. At the end of the incubation, PBMCs were washed with PBS and stained with Zombie Yellow Viability Stain. PBMCs were then washed, stained with antiCD3-Ax700, anti-CD4-PC5.5, and anti-CD8-PE-CF594 (clone RPAT8; BD 562282) and analyzed as above. Proliferation was assessed by cell trace ${ }^{\mathrm{dim}}$ populations.

Primary and secondary outcomes. The primary outcome was determined by FN- $\gamma / \mathrm{IL}-2$ FluoroSpot results at 30 days after the last dose of vaccine in each group. The effects of vaccine, age, and prior $\mathrm{ZV}$ administration on the primary outcome were prespecified objectives. Secondary outcomes were flow cytometric enumeration of Tem cells, Teff cells, Tregs, and exhausted $\mathrm{CD} 4^{+}$and $\mathrm{CD} 8^{+} \mathrm{T}$ cells and identifying responses that clearly differentiated between the 2 vaccines. Description of adverse events was also a secondary objective.

Statistics. Frequencies (\%) or means and SD were calculated for baseline patient demographics. To evaluate associations between peak response and 1-year FluoroSpot and vaccine, linear regression models adjusting for baseline values were constructed. Age, sex, and booster status were evaluated as covariates and excluded from the models if not found significant $(P<0.05)$. A post hoc mediation analysis was conducted to determine whether the effects of vaccine on persistence of Th1 responses at 1 year were mediated through PMR responses. For each mediation analysis, 2 regression models were estimated per the methods outlined by Tingley et. al (60). The ADE was estimated directly from the regression coefficient describing the PMR-adjusted relationship between vaccine and persistence of Th1. The ACME was estimated using the product of coefficients method and testing using bootstrapping. The gE- and VZV-specific $\mathrm{CD}^{+}$and $\mathrm{CD}^{+} \mathrm{T}$ cell differentiation profiles were compared at peak response between $\mathrm{gE}$ and $\mathrm{ZV}$ stimulation using a Tobit regression model ( $\mathrm{R}$ function vglm from package VGAM) (61) to account for the lower detection limit in the flow cytometry data. $\mathrm{T}$ cell differentiation profiles were log transformed, and models were adjusted for baseline response, with the threshold set at 0.005 for CD4 and 0.01 for CD8, reflecting their detection thresholds. Linear regression models similar to FluoroSpot were used to characterize peak response proliferation to vaccine, using log-transformed values and adjusting for baseline.

Flow cytometry data were expressed as the ratio of counts in VZVor gE-stimulated over mock-stimulated wells; ratios were log transformed prior to analysis. For observations where the mock-stimulated result was 0 , the participant's lowest mock cell percentage from an alternative visit was imputed, and when all mock-stimulated cell percentages were 0 , the lowest observed value from that participant was imputed. Similarly, for observations where a stimulated cell percentage was 0 , the lowest cell count for that participant was imputed. For parameters where more than $3 \%$ of the data were reported as 0 s, sensitivity analyses were conducted to evaluate the impact of imputation and compared with the imputed results. Flow parameters with a median VZV- or gE-stimulated-to-mock-stimulated ratio below 1.1 were not considered for analyses; these parameters were considered to have too large of a signal-to-noise ratio to be important in differentiating vaccine responses. To evaluate associations between flow parameters and the vaccine group, linear regression models were constructed for each parameter of interest, adjusting for baseline value. Age, sex, and booster status were evaluated as covariates and excluded from the models if not found significant $(P<0.05)$. To account for multiple comparisons, FDR corrections were implemented for each outcome, within cell type (CD4 and CD8) and for each stimulant (VZV and gE); unadjusted and adjusted $P$ values are reported.

Sample size justification. The primary statistical hypothesis for noninferiority tests (arm A vs. B and arm C vs. D) regarding VZV- and gE-specific ELISpot responses between the 2 vaccines (vaccine $1=$ $\mathrm{HZ} / \mathrm{su}$ and vaccine $2=\mathrm{ZV}$ is $\mathrm{HO}: \mathrm{R} 1 / \mathrm{R} 2 \leq 0.5$ versus $\mathrm{H} 1: \mathrm{R} 1 / \mathrm{R} 2>0.5$, where $\mathrm{R} 1$ is the fold-rise ratio of postvaccine response to baseline level for vaccine 1 and $\mathrm{R} 2$ is the fold-rise ratio for vaccine 2 at 30 days after vaccine 2). A ratio of 0.5 corresponds to a 2 -fold decrease of fold-rise ratio in vaccine 1 compared with vaccine 2 . Rejecting the null hypothesis (HO) at the 1-sided $\alpha=0.025$ level corresponds to the lower bound of the 2 -sided $95 \%$ CI on the fold-rise ratio (vaccine 1/vaccine 2) being greater than 0.5 and would lead to the conclusion that the response to live $\mathrm{ZV}$ is noninferior to the response to recombinant $\mathrm{gE}$ vaccine.

With 45 subjects enrolled in each arm, A and B, and an assumed $10 \%$ dropout rate, 40 subjects in each arm would be available for analysis and could achieve over $90 \%$ power to detect noninferiority (arm A vs. B) using a 1-sided 2-sample $t$ test with a significance level $(\alpha)$ of 0.025 . With 35 subjects enrolled in each arm, C and D, and an assumed $10 \%$ dropout rate, 31 subjects in each arm would be available for analysis and could achieve over $80 \%$ power to detect noninferiority (arm C vs. D) using a 1-sided 2-sample $t$ test with a significance level $(\alpha)$ of 0.025. The assumptions used in the power calculation are as follows: (a) 10\% dropout rate; (b) common SD of 0.41 (assumed an extra variability) on the log-transformed scale in each group based on previously published data (4) administering the live herpes ZV to subjects $60-70$ years of age; (c) noninferiority margin of 2 -fold with respect to fold-rise ratio; and (d) true ratio (vaccine 1/vaccine 2) for fold-rise ratio of 1.0.

Study approvals. This study in humans (NCT02114333) was reviewed and approved by the Colorado Multiple Institutions Review Board, University of Colorado School of Medicine. Subjects provided informed consent prior to participation in the study. 


\section{Author contributions}

AW and MJL designed the study, analyzed the data, and wrote the manuscript. MJL oversaw the clinical trial performance. AW oversaw the laboratory experiments. MEK, AH, and DR performed the statistical analysis and wrote sections of the manuscript. MJJ performed immunologic assays and wrote sections of the manuscript. NL performed the clinical activities. All authors reviewed the manuscript.

\section{Acknowledgments}

The authors thank Adriana Tovar-Salazar, Jennifer Canniff, and Emilie Jalbert for technical assistance and Zelalem Segano and
Elizabeth Barber at University of Colorado Denver for administrative support. We thank Giacomo Casabona, Romulo Colindres, and Eduardo de Gomensoro from the GSK clinical department for their support of this study. We thank Peter Vink, Lidia Oostvogels, Arnaud Didierlaurant, and Marie Bayle Normand from GSK for critical review of the manuscript. This work was supported by the GSK Investigator Initiated Study Program and NIH U19AI090023.

Address correspondence to: Adriana Weinberg, University of Colorado Anschutz Medical Campus, 12700 E. 19th Avenue, MS 8604, Aurora, Colorado, 80045, USA. Phone: 303.724.4480; Email: adriana.weinberg@ucdenver.edu.
1. Levin MJ. Zoster vaccines. In: Plotkin S, Orenstein W, Offitt P, Edwards KM, ed. Plotkin's vaccines. 7th E. Philadelphia, PA: Elsevier; 2017:1268-1281.

2. Gershon AA, Gershon MD. Pathogenesis and current approaches to control of varicellazoster virus infections. Clin Microbiol Rev. 2013;26(4):728-743.

3. Weinberg A, Levin MJ. VZV T cell-mediated immunity. Curr Top Microbiol Immunol. 2010;342:341-357.

4. Weinberg A, et al. Influence of age and nature of primary infection on varicella-zoster virusspecific cell-mediated immune responses. J Infect Dis. 2010;201(7):1024-1030.

5. Chen SY, et al. Incidence of herpes zoster in patients with altered immune function. Infection. 2014;42(2):325-334.

6. Buchbinder SP, et al. Herpes zoster and human immunodeficiency virus infection. J Infect Dis. 1992;166(5):1153-1156.

7. Arvin AM, Pollard RB, Rasmussen LE, Merigan TC. Cellular and humoral immunity in the pathogenesis of recurrent herpes viral infections in patients with lymphoma. J Clin Invest. 1980;65(4):869-878.

8. Levin MJ, et al. Varicella-zoster virus-specific immune responses in elderly recipients of a herpes zoster vaccine. J Infect Dis. 2008;197(6):825-835

9. Oxman $\mathrm{MN}$, et al. A vaccine to prevent herpes zoster and postherpetic neuralgia in older adults. NEngl JMed. 2005;352(22):2271-2284.

10. Schmader KE, et al. Effect of a zoster vaccine on herpes zoster-related interference with functional status and health-related quality-oflife measures in older adults. JAm Geriatr Soc. 2010;58(9):1634-1641.

11. Morrison VA, et al. Long-term persistence of zoster vaccine efficacy. Clin Infect Dis. 2015;60(6):900-909.

12. Tseng HF, et al. Declining effectiveness of herpes zoster vaccine in adults aged $\geq 60$ years. J Infect Dis. 2016;213(12):1872-1875

13. Sekkides O. Highlights from IDWeek 2015. Lancet Infect Dis. 2015;15(12):1383.

14. Baxter R, et al. Long-term effectiveness of the live zoster vaccine in preventing shingles: a cohort study. Am J Epidemiol. 2018;187(1):161-169.

15. Didierlaurent AM, Laupèze B, Di Pasquale A, Hergli N, Collignon C, Garçon N. Adjuvant system AS01: helping to overcome the chal- lenges of modern vaccines. Expert Rev vaccines. 2017;16(1):55-63.

16. Cunningham AL, et al. Efficacy of the herpes zoster subunit vaccine in adults 70 years of age or older. N Engl J Med. 2016;375(11):1019-1032.

17. Lal H, et al. Efficacy of an adjuvanted herpes zoster subunit vaccine in older adults. $N$ Engl J Med. 2015;372(22):2087-2096.

18. Chlibek R, et al. Long-term immunogenicity and safety of an investigational herpes zoster subunit vaccine in older adults. vaccine. 2016;34(6):863-868.

19. Pauksens K, et al. Persistence of Immune Response to an Adjuvanted Varicella-Zoster Virus Subunit Candidate vaccine for up to Year 9 in Older Adults. Poster presented at: ID Week 2017; October 4-8 2017; San Diego, CA. https:// idsa.confex.com/idsa/2017/webprogram/ Paper66091.html. Accessed July 31, 2018.

20. Cunningham AL, et al. Immune responses to a recombinant glycoprotein $\mathrm{E}$ herpes zoster vaccine in adults aged 50 years or older. J Infect Dis. 2018;217(11):1750-1760.

21. Shapiro ED, et al. The protective efficacy of polyvalent pneumococcal polysaccharide vaccine. NEngl JMed.1991;325(21):1453-1460.

22. Goodwin K, Viboud C, Simonsen L. Antibody response to influenza vaccination in the elderly: a quantitative review. Vaccine. 2006;24(8):1159-1169.

23. Didierlaurent AM, et al. Enhancement of adap tive immunity by the human vaccine adjuvant AS01 depends on activated dendritic cells. J Immunol. 2014;193(4):1920-1930.

24. Leroux-Roels $\mathrm{G}$, et al. Impact of adjuvants on CD4(+) T cell and B cell responses to a protein antigen vaccine: Results from a phase II, randomized, multicenter trial. Clin Immunol. 2016;169:16-27.

25. Coccia M, et al. Cellular and molecular synergy in AS01-adjuvanted vaccines results in an early IFN gamma response promoting vaccine immunogenicity. NPJvaccines. 2017;2:25.

26. Levin MJ, et al. Cellular and humoral responses to a second dose of herpes zoster vaccine administered 10 years after the first dose among older adults. J Infect Dis. 2016;213(1):14-22.

27. Smith JG, Liu X, Kaufhold RM, Clair J, Caulfield MJ. Development and validation of a gamma interferon ELISpot assay for quantitation of cellular immune responses to varicella-zoster virus. Clin Diagn Lab Immunol. 2001;8(5):871-879.
28. Laidlaw BJ, Craft JE, Kaech SM. The multifaceted role of CD4(+) T cells in CD8(+) T cell memory. Nat Rev Immunol. 2016;16(2):102-111.

29. Schmader KE, et al. Persistence of the efficacy of zoster vaccine in the shingles prevention study and the short-term persistence substudy. Clin Infect Dis. 2012;55(10):1320-1328.

30. Ehrlich AK, et al. AhR activation increases IL-2 production by alloreactive CD $4+\mathrm{T}$ cells initiating the differentiation of mucosalhoming Tim3+ Lag3+ Tr1 cells. Eur J Immunol. 2017;47(11):1989-2001.

31. Ma QY, Huang DY, Zhang HJ, Wang S, Chen XF. Function and regulation of LAG3 on CD4+CD25T cells in non-small cell lung cancer. Exp Cell Res. 2017;360(2):358-364.

32. Sakuishi K, et al. TIM3+FOXP3+ regulatory $\mathrm{T}$ cells are tissue-specific promoters of $\mathrm{T}$-cell dysfunction in cancer. Oncoimmunology. 2013;2(4):e23849.

33. Levin MJ, et al. Varicella-zoster virus DNA in blood after administration of herpes zoster vaccine. J Infect Dis. 2018;217(7):1055-1059.

34. Chlibek R, et al. Safety and immunogenicity of three different formulations of an adjuvanted varicella-zoster virus subunit candidate vaccine in older adults: a phase II, randomized, controlled study. vaccine. 2014;32(15):1745-1753.

35 . Sei JJ, et al. Effector and central memory polyfunctional CD4(+) T cells are boosted upon ZOSTAVAX $\left({ }^{\circledR}\right)$ vaccination. Front Immunol. 2015;6:553.

36. Tyring SK, et al. Varicella-zoster virus-specific enzyme-linked immunospot assay responses and zoster-associated pain in herpes zoster subjects. Clin vaccine Immunol. 2012;19(9):1411-1415.

37. Vermeulen JN, et al. Safety, tolerability, and immunogenicity after 1 and 2 doses of zoster vaccine in healthy adults $\geq 60$ years of age. vaccine. 2012;30(5):904-910.

38. Akondy RS, et al. Origin and differentiation of human memory CD8 T cells after vaccination. Nature. 2017;552(7685):362-367.

39. Qi Q, et al. Defective T memory cell differentiation after varicella zoster vaccination in older individuals. PLoS Pathog. 2016;12(10):e1005892.

40. Ouwendijk WJ, Laing KJ, Verjans GM, Koelle DM. T-cell immunity to human alphaherpesviruses. Curr Opin Virol. 2013;3(4):452-460.

41. Vossen MT, Gent MR, Weel JF, de Jong MD, van Lier RA, Kuijpers TW. Development of virusspecific CD4+ T cells on reexposure to varicella- 
zoster virus. J Infect Dis. 2004;190(1):72-82.

42. Frey CR, Sharp MA, Min AS, Schmid DS, Loparev $\mathrm{V}$, Arvin AM. Identification of CD8+ T cell epitopes in the immediate early 62 protein (IE62) of varicella-zoster virus, and evaluation of frequency of CD8+ T cell response to IE62, by use of IE62 peptides after varicella vaccination. J Infect Dis. 2003;188(1):40-52.

43. Zangeneh Z, Golmoghaddam H, Emad M, Erfani N, Doroudchi M. Elevated PD-1 expression and decreased telomerase activity in memory $\mathrm{T}$ cells of patients with symptomatic Herpes Zoster infection. Cell Mol Biol (Noisy-le-grand). 2014;60(4):13-21.

44. Mikloska Z, Rückholdt M, Ghadiminejad I, Dunckley H, Denis M, Cunningham AL. Monophosphoryl lipid A and QS21 increase CD8 T lymphocyte cytotoxicity to herpes simplex virus- 2 infected cell proteins 4 and 27 through IFN-gamma and IL-12 production. J Immunol. 2000;164(10):5167-5176.

45. den Brok MH, et al. Saponin-based adjuvants induce cross-presentation in dendritic cells by intracellular lipid body formation. Nat Commun. 2016;7:13324.

46. Laing KJ, et al. Zoster vaccination increases the breadth of CD $4+\mathrm{T}$ cells responsive to varicella zoster virus. J Infect Dis. 2015;212(7):1022-1031.

47. Koelle DM, Johnson MJ, Laing KJ, Kitchington R, Campbell VL, Levin MJ, and Weinberg A. 43rd International Herpesvirus Workshop. Vancouver,
BC, Canada; 2018:Abstract 126.

48. Weinberg A, Johnson MJ, Kroehl M, Lang N, Reinhold D, Levin MJ. A comparison of the immunogenicity of a live attenuated herpes zoster vaccine $(\mathrm{ZV})$ and the recombinant $\mathrm{gE} / \mathrm{ASO}_{\mathrm{B}}$ candidate vaccine in older adults. J Immunol. 2017;198(1 Supplement):225.1-225.1.

49. Grupping K, et al. Immunogenicity and safety of the $\mathrm{HZ} / \mathrm{su}$ adjuvanted herpes zoster subunit vaccine in adults previously vaccinated with a live attenuated herpes zoster vaccine. J Infect Dis. 2017;216(11):1343-1351.

50. Levin MJ, Cai GY, Manchak MD, Pizer LI. Varicellazoster virus DNA in cells isolated from human trigeminal ganglia. JVirol.2003;77(12):6979-6987.

51. Levin MJ. Varicella-zoster virus and virus DNA in the blood and oropharynx of people with latent or active varicella-zoster virus infections. J Clin Virol. 2014;61(4):487-495.

52. Papaevangelou V, et al. Subclinical VZV reactivation in immunocompetent children hospitalized in the ICU associated with prolonged fever duration. Clin Microbiol Infect. 2013;19(5):E245-E251.

53. Wilson A, Sharp M, Koropchak CM, Ting SF, Arvin AM. Subclinical varicella-zoster virus viremia, herpes zoster, and $\mathrm{T}$ lymphocyte immunity to varicella-zoster viral antigens after bone marrow transplantation. J Infect Dis. 1992;165(1):119-126.

54. Cohrs RJ, Gilden DH. Prevalence and abundance of latently transcribed varicellazoster virus genes in human ganglia. J Virol.
2007;81(6):2950-2956.

55. Ouwendijk WJ, et al. Restricted varicellazoster virus transcription in human trigeminal ganglia obtained soon after death. J Virol. 2012;86(18):10203-10206.

56. Zerboni L, Sen N, Oliver SL, Arvin AM. Molecular mechanisms of varicella zoster virus pathogenesis. Nat Rev Microbiol. 2014;12(3):197-210.

57. Dendouga N, Fochesato M, Lockman L, Mossman S, Giannini SL. Cell-mediated immune responses to a varicella-zoster virus glycoprotein $E$ vaccine using both a TLR agonist and QS21 in mice. vaccine. 2012;30(20):3126-3135.

58. Weinberg A, et al. Optimization and limitations of use of cryopreserved peripheral blood mononuclear cells for functional and phenotypic T-cell characterization. Clin vaccine Immunol. 2009;16(8):1176-1186.

59. Weinberg A, et al. Optimization of storage and shipment of cryopreserved peripheral blood mononuclear cells from HIV-infected and uninfected individuals for ELISpot assays. JImmunol Methods. 2010;363(1):42-50.

60. Tingley D, Yamamoto T, Hirose K, Keele L, Imai K. Mediation: R package for causal mediation analysis. Journal of Statisical Software. https:// www.jstatsoft.org/article/view/v059i05. Accessed July 31, 2018.

61. Yee TW. Vector Generalized Linear and Additive Models: With an Implementation in R. New York, NY: Springer; 2015. 